\title{
Long-term sulfuric and hydrochloric acid resistance of silica fume and colemanite waste reinforced metakaolin-based geopolymers
}

\author{
Yurdakul Aygörrmez (Main and Corresponding Author) \\ Yildiz Technical University, Department of Civil Engineering Davutpasa Campus \\ 34220, Esenler, Istanbul (Turkey) \\ aygormez@yildiz.edu.tr \\ https://orcid.org/0000-0001-7405-2450 \\ Orhan Canpolat \\ Yildiz Technical University, Department of Civil Engineering Davutpasa Campus \\ 34220, Esenler, Istanbul (Turkey) \\ canpolat@yildiz.edu.tr \\ https://orcid.org/0000-0003-2744-7876
}

Manuscript Code: 22981

Date of Acceptance/Reception: 29.05.2021/24.10.2020

DOI: 10.7764/RDLC.20.2.72

\section{Abstract}

For this paper, silica fume (SF), slag (S), and colemanite waste (C) were added to metakaolin (MK)-based geopolymer composites and exposed to $10 \%$ (by volume) hydrochloric acid $(\mathrm{HCl})$ and sulfuric acid $\left(\mathrm{H}_{2} \mathrm{SO}_{4}\right)$ solutions for up to 12 months. Geopolymer composites were examined in terms of weight loss, compressive strength, and flexural strength at 3, 6, and 12 months in solutions. Furthermore, Scanning Electron Microscopy (SEM), Microcomputed Tomography (micro-CT), Fourier Transform Infrared Spectroscopy (FTIR), and X-ray Diffraction (XRD) analyses were carried out to examine the microstructure before and after acid attacks. An important decrease in flexural and compressive strengths was seen when geopolymer mortars were subjected to sulfuric and hydrochloric acid attacks. The main cause of this situation is the deterioration of the oxy-aluminum bridge (-Al-Si-O) when exposed to sulfuric and hydrochloric acid. The oxy-aluminum bridge (-Al-Si-O), the primary factor in the geopolymer matrix, plays a significant role in consolidating the gel and enhancing the bond formed between the matrix components. Despite this, geopolymer mortar samples maintain the aluminosilicate structure. Compared to hydrochloric acid, sulfuric acid is a stronger solution, resulting in a greater loss of compressive and flexural strengths.

Keywords: geopolymer, metakaolin, colemanite waste, silica fume, sulfuric acid, hydrochloric acid.

Introduction

Despite the advantages of Portland Cement, it can be damaged by exposure to acid, sulfates, and seawater as well as atmospheric carbon dioxide emissions (Elyamany et al., 2018; Rivera et al., 2014). Geopolymers are an important potential source of construction material because they produce low $\mathrm{CO}_{2}$ emissions (Zhang et al., 2014). Metakaolin raw material has pozzolanic properties obtained through the calcining of kaolin between temperatures of 500 and $900{ }^{\circ} \mathrm{C}$ (Yang et al., 2017). Additionally, it produces a strong reaction due to activator solutions and enhances compressive and flexural strengths (Belmokhtar et al., 2017). Davidovits (2020) found that metakaolin and slag-based geopolymer composites showed the best results in terms of mechanical properties and durability. Geopolymerization is based on the metakaolin type, the amount and concentration of activator solutions, and the curing conditions (Chen et al., 2016). Waste materials were evaluated and found to be useful in geopolymer production. The biggest boron deposits in the world are found in Turkey. Boron mines provide resources used in a variety of fields such as energy, medicine, and agriculture. Boron waste colemanite is used as a mineral additive in the cement and concrete sectors (Sevim, 2011). Kula et al. (2001) researched the influence of colemanite on the mortar's engineering properties and found that $\mathrm{B}_{2} \mathrm{O}_{3}$ content had the greatest effect. Colemanite wastes had a positive influence on the mechanical properties of the mortars when evaluated as an additive of up to 10\% (Ali et al., 2020; Aygörmez, Canpolat, \& Al-mashhadani, 2020a, 2020b; Uysal et al., 2018).

Concrete structures can be exposed to different types of inorganic and organic acids, and acidic environments are a natural byproduct of industrial, agricultural, and urban activities (Kwasny et al., 2018). The effects of acid depend on the type and quality of the concrete, the type of acid, concentration, $\mathrm{pH}$, and permeability of the environment surrounding the concrete (Aiken et al., 2018). The main focus of this study was on high concentrations of sulfuric acid and hydrochloric acid. These acids cause severe deterioration of hardened cement paste and remove $\mathrm{Fe}^{3+}$ and $\mathrm{Al}^{3+}$ ions at low pH (Aiken et al., 2018; Kwasny et al., 2018). The combination of acid attack and the subsequent effects increases in porosity and permeability results in loss of alkalinity, weight, and compressive and flexural strengths. At the same 
time, the $\mathrm{Ca}^{2+}$ ion concentration in hardened cement paste is not maintained and the microstructure becomes more susceptible to attack (Khan et al., 2019).

Portland Cement-based materials generally have a low resistance to the influence of acid, resulting in reduced service life in exposed structures, and damage to buildings has many social, environmental, and material consequences. As a precaution against chemical attack, a physical barrier to exposure can be created by applying layers of protective coatings and sealants to the concrete surface to prevent acids from entering the microstructure of the concrete (Aguiar et al., 2008; Almusallam et al., 2003); however, these solutions are costly as they require labor-intensive (Tahri et al., 2017). Recently, due to its ceramic-like microstructure, geopolymer binders have offered a promising solution against the acid effect. Extensive studies have been carried out on geopolymers as they hold important advantages in terms of acid resistance. Geopolymers can provide acid-resistant products that may be used for sewage pipes, water tanks, and other projects in caustic environmental conditions.

Many studies have been investigated the performance of geopolymer composites and Portland concrete under the influence of acid. Researchers have studied the durability of geopolymers using fly ash, slag, and other waste products, but more information is needed on the resistance of metakaolin-based geopolymers to acids. Besides, low concentrations were generally preferred in these studies that investigated the acid effect. Sulfuric acid and hydrochloric acid are found on a large scale in many different sectors such as the food industry, mining, sewer pipes, nuclear power plants. Especially for uranium enrichment in nuclear power plants, uranium metal is easily dissolved in sulfuric acid and hydrochloric acid, forming uranium salts. Due to this situation, high concentrations (i.e., $10 \%$ by volume) of sulfuric and hydrochloric acid solutions were applied for a long time (1 year) to determine how the geopolymer materials behave in these intense acid environments without losing their mechanical and physical integrity and to determine the limit condition of the material against acid. Thus, an alternative product was investigated in the face of these situations. In addition, not only metakaolin-based geopolymer samples were investigated against the acid effect, but also the benefits of colemanite waste and silica fume against acid effects were investigated. Colemanite waste and silica fume were substituted up to $20 \%$ in the metakaolin-based geopolymer composites. In this study, three different tests (weight loss, compressive and flexural strengths) were performed to determine physical properties. The geopolymer samples were tested after 3, 6, and 12 months. Besides, four different microstructure analyzes (SEM, XRD, FTIR, and micro-CT) were carried out before and after the test to support the physical conditions.

Methodology

\section{Materials}

In this study, metakaolin (specific gravity is 2.52) was evaluated as the main raw material of the mortar. The activation temperature for the conversion of the kaolin to metakaolin was set as $750^{\circ} \mathrm{C}$. The ratio of silica + alumina + iron oxide is $97.18 \%$ and its pozzolanic activity is high. The percentage of metakaolin remaining on the $45 \mu \mathrm{m}$ sieve is $0.70 \%$, so it is fine-grained. This indicates that it will be very reactive because smaller particles have a higher Blaine surface area and are therefore more prone to reaction. Along with metakaolin, slag, colemanite, and silica fume were also used in the production of geopolymer. The specific gravities of slag, colemanite, and silica fume are 2.91, 2.42, and 2.20, respectively. The Blaine-specific surface areas of the silica fume and slag are $20,000 \mathrm{~m}^{2} / \mathrm{kg}$ and $450 \mathrm{~m}^{2} / \mathrm{kg}$, respectively. Table 1 shows the chemical composition of the materials.

Table 1. The materials' chemical compositions. (Self-Elaboration).

\begin{tabular}{ccccccccccc}
\hline $\begin{array}{c}\text { Chemical } \\
\text { analysis, } \%\end{array}$ & $\mathrm{SiO}_{2}$ & $\mathrm{Al}_{2} \mathrm{O}_{3}$ & $\mathrm{Fe}_{2} \mathrm{O}_{3}$ & $\mathrm{TiO}_{2}$ & $\mathrm{CaO}$ & $\mathrm{MgO}$ & $\mathrm{K}_{2} \mathrm{O}$ & $\mathrm{Na}_{2} \mathrm{O}$ & $\mathrm{B}_{2} \mathrm{O}_{3}$ & L.O.I. \\
\hline $\mathrm{MK}$ & 56.10 & 40.25 & 0.85 & 0.55 & 0.19 & 0.16 & 0.55 & 0.24 & - & 1.11 \\
\hline $\mathrm{S}$ & 40.60 & 12.83 & 1.37 & 0.75 & 36.08 & 6.87 & 0.68 & 0.79 & - & 0.03 \\
\hline $\mathrm{SF}$ & 90.58 & 1.37 & 0.15 & - & 0.35 & 4.02 & 2.55 & 0.58 & - & 0.40 \\
\hline $\mathrm{C}$ & 5.00 & 0.40 & 0.08 & - & 26.02 & 3,00 & - & 0.50 & 40.00 & 25.00
\end{tabular}

Standard (Rilem) sand (in conformity with BS EN 196-1) was utilized for the preparation of the geopolymer mortars. The specific gravity and water absorption ratio of standard sand are 2.6 and 1.276, respectively. Sodium hydroxide and silicates were used as alkali activators. A blend of sodium hydroxide $(12 \mathrm{M})$ and sodium silicate $\left(\mathrm{SiO}_{2} / \mathrm{Na}_{2} \mathrm{O}=3.29\right)$ was used. 


\section{Mortar production and heat treatment}

Cementless mortars were produced by using Standard sand, metakaolin, silica fume, colemanite, slag, sodium hydroxide, and sodium silicate. Mortar mixtures were prepared by weight to get sand:binder ratio of 2.5 , a binder:sodium hydroxide ratio of 3, and a binder:sodium silicate ratio of 1.5 for $450 \mathrm{~g}$ of binder material. No extra water was added when preparing the mixture. Water was used when preparing a sodium hydroxide solution. To prepare a $12-$ molar sodium hydroxide solution, $480 \mathrm{~g}$ of sodium hydroxide pellets were dissolved in distilled water to be completed to 1 liter. Therefore, instead of the water/binder ratio, the sodium hydroxide/binder ratio and sodium silicate/binder ratio have been taken into consideration. To give a more detailed explanation for the mixture, series with $100 \%$ metakaolin, which is the control sample from 5 series, has been taken into consideration. For other series, only the binder material has changed as seen in Table 2 . The preparation of the control mixture ( $100 \%$ metakaolin) was as follows: $450 \mathrm{~g}$ of metakaolin were mixed with pre-prepared sodium hydroxide (12M) and sodium silicate mixture using a mixer drill. The activator solution was blended with the raw material as a ratio of 1:1. Later, $60 \mathrm{~g}$ ( $13 \%$ relative to the binder) of slag were mixed to increase the calcium content and reduce the setting time. The slag has a high Ca composition of $36 \%$, as well as a high content of silica and alumina. Slag was used in this study to be effective in the curing behavior of geopolymers, not as a binder material. Due to this situation, slag was added to the mixture after mixing the binder and alkali activator. In this respect, it is important for early and late age characteristics. Finally, standard sand was used so that the sand:binder ratio was 2.5:1. The procedure followed in the preparation of the mixture is shown in Figure 1.

Figure 1. Geopolymer mixing procedure. (Self-Elaboration).

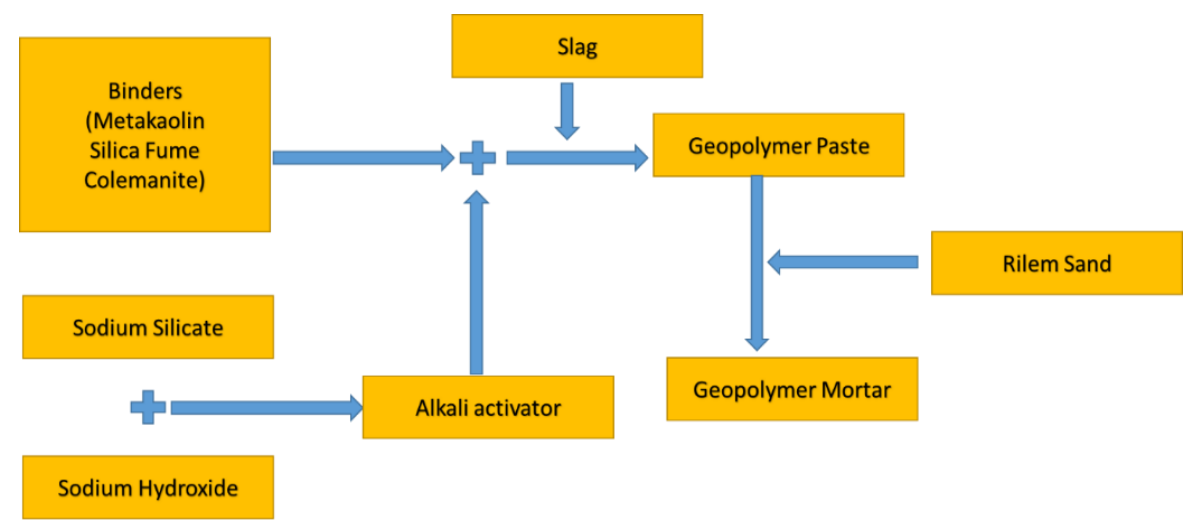

Next, the mixture was put into molds ( $40 \times 40 \times 160 \mathrm{~mm}$ prisms and $50 \mathrm{~mm}$ side cubes) and shaken. After mixing, the samples were removed from the molds with the slag effect after two hours and kept at room temperature $\left(23 \pm 2{ }^{\circ} \mathrm{C}\right)$ and relative humidity ( $50 \pm 4 \%$ ) for 24 hours. Here, the heat curing was not applied immediately, but one day after its production. The main reason for this is that the high relative humidity applied before the heat curing contributes to the improvement of compressive and flexural strengths and reduction of shrinkage. The geopolymer specimens were then placed in nonflammable oven bags before heat curing to prevent evaporation in the drying oven at $60^{\circ} \mathrm{C}$ for three days. After curing, the specimens were taken out of the oven bags and put into plastic bags. The geopolymer samples were stored until 28 days for the target tests. In addition to the mixture prepared with $100 \%$ metakaolin, silica fume and colemanite were substituted for up to $20 \%$. A total of five series were prepared, and the pure metakaolin mixture is denoted as MK. Mixtures with $10 \%$ and $20 \%$ added silica fume are shown as 10 SF and 20 SF, respectively. Likewise, $10 \%$ and $20 \%$ colemanite were added to the mixtures denoted as $10 \mathrm{C}$ and $20 \mathrm{C}$, respectively. The geopolymer series are shown in Table 2.

\begin{tabular}{|c|c|c|c|c|c|c|c|}
\hline Mix ID & Metakaolin & $\begin{array}{l}\text { Silica } \\
\text { Fume }\end{array}$ & Colemanite & Slag & $\begin{array}{l}\mathrm{NaOH} \\
(12 \mathrm{M})\end{array}$ & $\mathrm{Na}_{2} \mathrm{SiO}_{3}$ & Sand \\
\hline MK & 450 & - & - & 60 & 150 & 300 & 1125 \\
\hline $10 \mathrm{SF}$ & 405 & 45 & - & 60 & 150 & 300 & 1125 \\
\hline $20 \mathrm{SF}$ & 360 & 90 & - & 60 & 150 & 300 & 1125 \\
\hline $10 \mathrm{C}$ & 405 & - & 45 & 60 & 150 & 300 & 1125 \\
\hline $20 C$ & 360 & - & 90 & 60 & 150 & 300 & 1125 \\
\hline
\end{tabular}




\section{Acid attack test}

After 28 days, the acid attack tests were applied. Before the acid attack, the samples were placed in a drying oven and exposed to $105^{\circ} \mathrm{C}$ for 24 hours. This method was applied to ensure that the solutions were absorbed more effectively. Then, the geopolymer mortars were exposed to $10 \%$ (by volume) hydrochloric acid $(\mathrm{HCl}$ ) and $10 \%$ (by volume) sulfuric acid $\left(\mathrm{H}_{2} \mathrm{SO}_{4}\right)$ solutions in plastic storage boxes at room temperature for 12 months. The solutions were renewed at the 1st, $2 \mathrm{nd}$, 3rd, and 6th months to maintain the solutions' concentration. Four units of solution (by volume) per one unit of the sample were placed in the plastic storage boxes. After 3, 6, and 12 months, compressive and flexural strengths, and weight losses were recorded. The samples were dried at room temperature $\left(23 \pm 2{ }^{\circ} \mathrm{C}\right)$ immediately after removal from the solution. A wire brush was then used to clean the surfaces. Fifty-millimeter cubes were used for compressive strength tests, and prismatic molds were used for flexural strength tests. Each test was performed using three samples, and the data obtained was calculated according to the average of the three samples. Before and after the tests, SEM, XRD, FTIR, and micro-CT analyzes were carried out.

Results and discussion

\section{Visual inspection}

Visual inspections of the inner core and the outer surface of the geopolymer mortars were made after the acid attacks. The state of the inner core of the geopolymer samples at the end of the flexural strength test is shown in Figure 2. From this photo, the area of action of sulfuric acid can be seen. A two-layer image is formed. The outer surface's visual appearance of the geopolymer samples after the sulfuric acid effect is shown in Figure 3. Deterioration is seen on the surface of samples exposed to sulfuric acid. Since the acid solution concentration is high, damage to the surface is high. As the test period progresses, the surface becomes slightly softer, although it is not easily scratched with a fingernail. Nevertheless, the samples maintain their stability.

The outer surface of the samples after exposure to hydrochloric acid is shown in Figure 4. The samples exposed to the hydrochloric acid solution have a similar appearance with only minor signs of deterioration. Even with the effect of a $10 \%$ hydrochloric acid solution, geopolymer samples are not greatly damaged compared to samples exposed to sulfuric acid. Also, it can be observed that the samples maintain their stability.

Visual examination of exposed geopolymer mortar samples shows a minimal physical change. No significant physical damage can be observed and a solid structure is maintained. Only some erosion occurs in the corners and near the edge areas; however, in the case of exposure to $\mathrm{H}_{2} \mathrm{SO}_{4}$, more visible surface degradation occurs, and the accumulation of white flaky material can be observed on sample surfaces. The main reason for this difference in behavior between the two acid solutions is linked to the formation of gypsum crystals that form high volumetric expansions and cause dispersal of the surface layer. However, it can be observed that physical deterioration doesn't reflect the order of the mortars' resistance to acid (Vafaei et al., 2018).

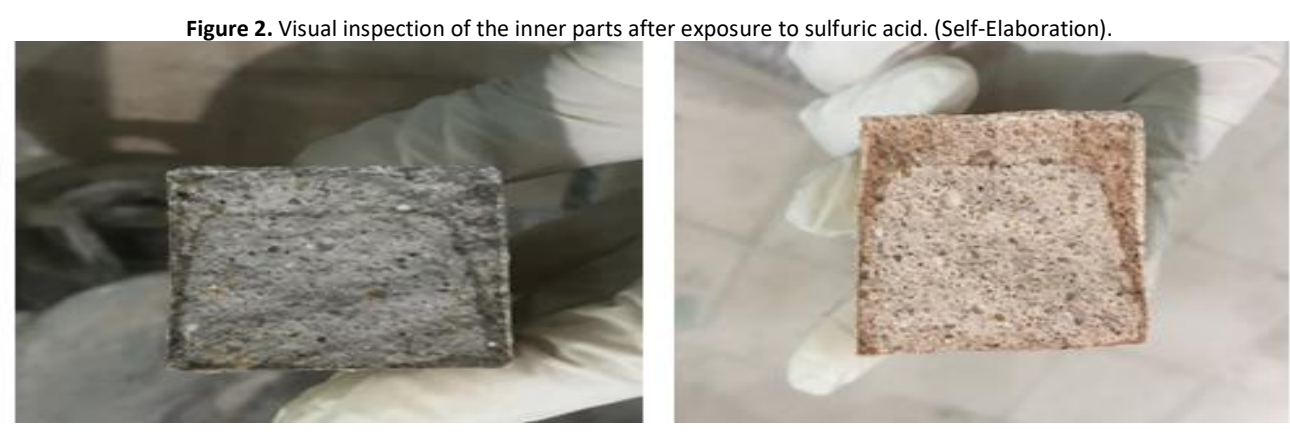


Figure 3. Visual inspection with sulfuric acid effect in all samples a) over 6 months, b) over 12 months. (Self-Elaboration).
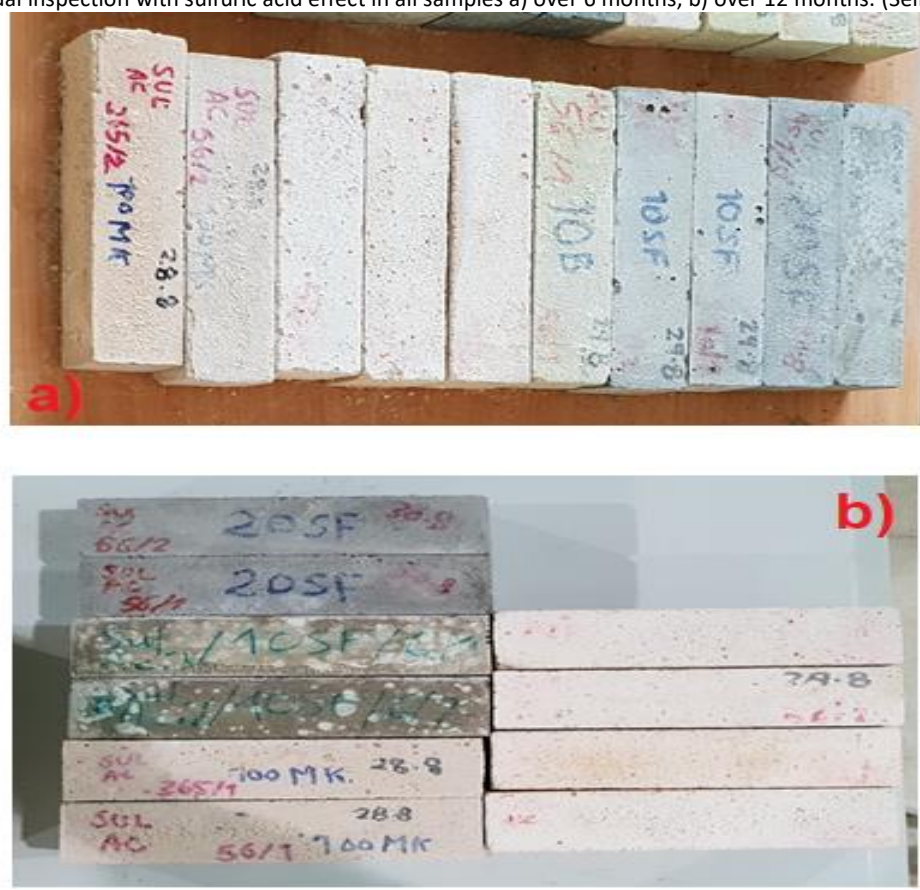

Figure 4. Visual inspection with hydrochloric acid effect in all samples a) over 6 months, b) over 12 months. (Self-Elaboration)
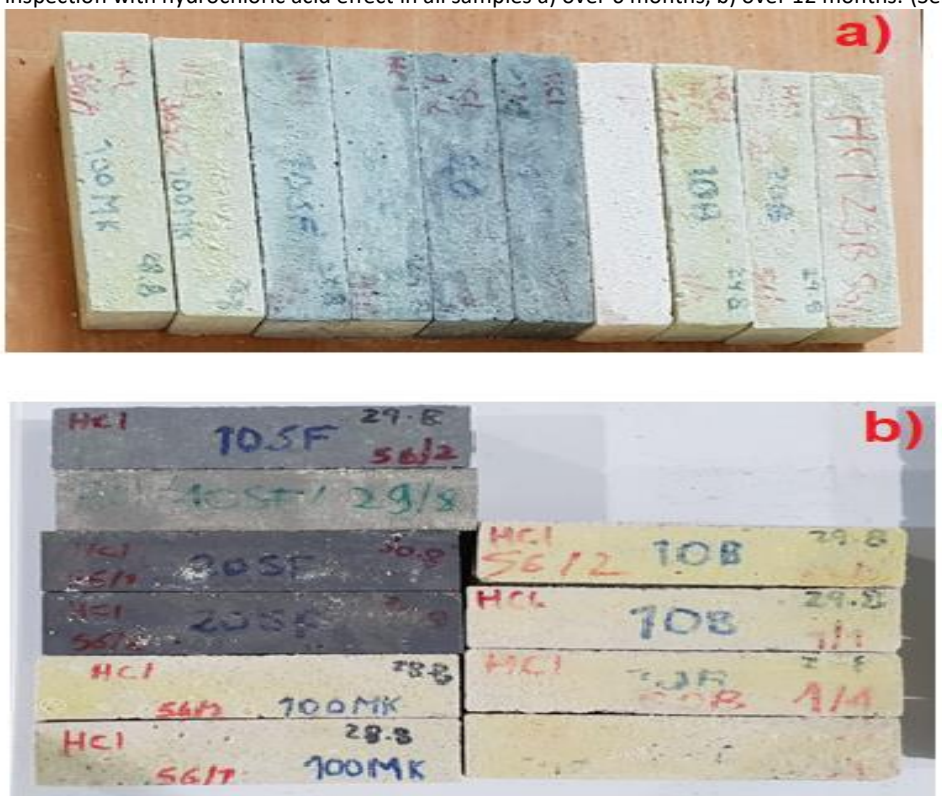

\section{Compressive and flexural strength results}

The compressive strength results were checked with the 28-day results (Figs. 5-6). Metakaolin has the potential to partially replace cement. In this sense, it is an important binding material for geopolymer, which is a cementless product. In this case, the acceleration of the pozzolanic reaction and its fineness play an important role. Thus, significant initial compressive and flexural strength results are obtained by using only Metakaolin-based geopolymer production (Aygörmez, Al-mashhadani, et al., 2020c). However, using different materials can increase these results. For all samples, maximum deterioration was observed after 365 days of exposure. The samples' residual compressive strength results at any given time depended on the samples' initial compressive strength and the total damaged cross-sectional area; therefore, higher strength results were obtained after exposure to acid for samples 20SF and 10C, each with high initial compressive strength. If a more specific explanation is required, it has been shown that colemanite performs well at the task of filling voids and creating a protective layer by using it as an additive up to $10 \%$, thus helping to improve mechanical properties based on permeability properties of the geopolymeric matrix (Celik et al., 2018; Uysal et al., 2018). 
According to the literature, it is thought that after a critical ratio $(10 \%)$, some anions and cations formed by unstable compounds in the system interfere with the cement activation mechanism and cause a decrease in compressive strength. As a general result, silica fume has a favorable influence on the properties when used as an additive of up to $20 \%$. Since silica fume is thin, it can reduce the size of the voids and has been shown to improve geopolymeric matrices by decreasing the voids ratio, but it was also observed to have an unfavorable effect on the mortar's properties by decreasing its workability with the use (Bani Ardalan et al., 2017; Wu et al., 2019). This can be explained by the fact that a high Blaine-specific surface area of silica fume particles reduces the workability of the mortars. Using sulfuric acid, 29.69, 15.32, and 10.67 MPa of residual compressive strengths were obtained for sample $20 \mathrm{SF}$ after 3,6 , and 12 months, respectively. For sample $10 \mathrm{C}$, the compressive strengths were $26.63,13.64$, and $7.73 \mathrm{MPa}$ after 3,6 , and 12 months, respectively.
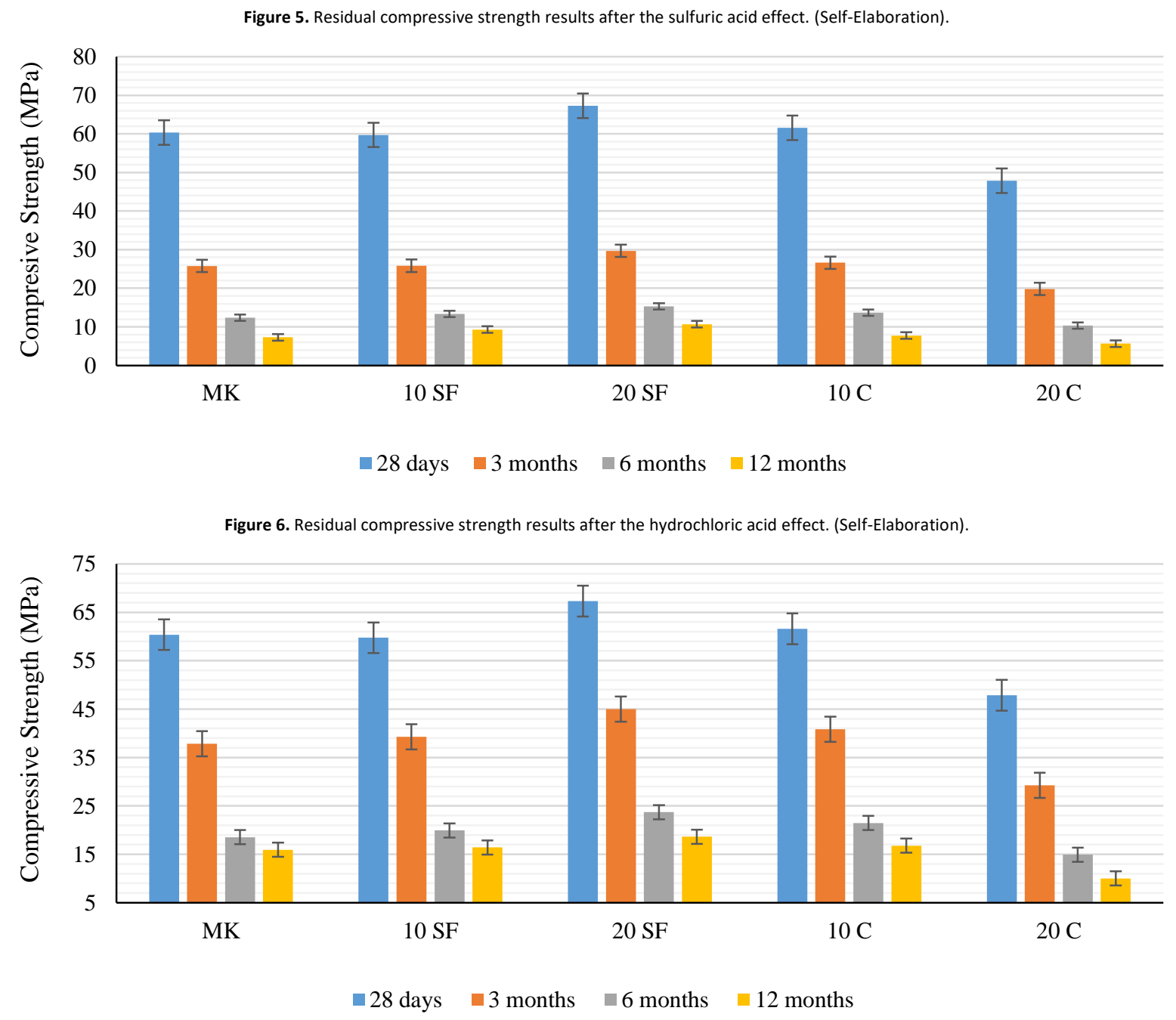

Compressive strength loss was observed in sulfuric and hydrochloric acids when exposed to high exposure. The main cause of the reduction in compressive strength is the deterioration of the (-Al-Si-O) in the geopolymeric gel under acid attack because the oxy-aluminum bridge is the primary factor in the geopolymer matrix that plays a significant role in consolidating the gel and enhancing the bonds formed within the matrix (Chang et al., 2005; Nematollahi et al., 2017). This situation can be explained in more detail. The term poly(sialate) is used in the chemical description of the geopolymer. Poly(sialates) is an abbreviation for silicon-oxo-aluminate and are ring and chain polymers containing $\mathrm{Al}^{3+}$ and $\mathrm{Si}^{4+}$ in 4-fold coordination with oxygen. The rings and chains are cross-linked when formed by a sialate Si-O-Al bridge. The alumino-silicate bridge possessed by the geopolymer is attacked by the action of hydrogen ions $\left(\mathrm{H}^{+}\right)$consisting of $\mathrm{HCl}$ and $\mathrm{H}_{2} \mathrm{SO}_{4}$ acid ionization. $\mathrm{H}^{+}$ions break down the alumino-silicate network (-Al $-\mathrm{O}-\mathrm{Si}-\mathrm{O}-$ ) at aluminum sites, revealing silicic acid $\left(\mathrm{Si}(\mathrm{OH})_{4}\right)$ and aluminum ions $\left(\mathrm{Al}^{3+}\right)$. Thus, by the breaking of the oxy-aluminum bridge $(-\mathrm{Al}-\mathrm{O}-\mathrm{Si}-\mathrm{O})$, the geopolymer becomes sensitive to acid (Chindaprasirt et al., 2013). Compressive strength loss also occurs due to the depolymerization of geopolymeric products and the formation of zeolites; however, the geopolymerization mechanism produces reaction products due to strong alumina-silicate bonds which are not easily affected by acid, thus good results are obtained. Geopolymer stability in a caustic environment depends on the crystalline phase formation, which means more formation of the crystalline phase provides greater stability (Mehta \& Siddique, 2017). 
Another factor in the resistance of the binder to the acidic solution is the morphology of the sample because it is thought that pore size has a significant effect on durability. Due to the low porosity, threshold pore diameter, and higher total pore surface area of geopolymer composites, there is limited acid diffusion into the microstructure of the geopolymer as compared to Portland Cement because the geopolymer creates a layer that protects the cement from exposure to acid and thus reduces the degree of degradation (Singh et al., 2015). The addition of silica fume to the mortar base improves the residual compressive strength because the addition of silica fume creates a more compact structure, which prevents sulfuric acid from entering the mortar. The colemanite has a favorable influence on the results when is substituted up to $10 \%$ in the mortar. Since silica fume and colemanite additives reduce the voids ratio, they reduce acid diffusion and the rate of deterioration as well. By intensifying the interfacial transition region formed in the geopolymer, a less porous and nonpermeable aggregate-paste interface forms, and the effect is to restrict the passage of acidic fluids by the capillary effect. The lower input of harmful ions can be considered to be associated with a decrease in the effective water:solid ratio, resulting in a dense geopolymer microstructure with reduced porosity (Afridi et al., 2019; Mobili et al., 2016).

The low Ca content in the geopolymer material is the other factor that provides superior durability compared to the Portland binder. Geopolymer composites show better performance in acidic environments because geopolymer binder materials are not as lime-bound as Portland cement and have lower calcium content. On the other hand, the main cause for the compressive strength decrease in Portland cement is the presence of calcium oxide, which triggers gypsum and ettringite formation with the passage of harmful ions from the acid solution to the matrix. This triggers expansion, cracking, and spreading in Portland cement and results in compressive strength loss (Omrane et al., 2017).

The degree of deterioration of geopolymer samples for hydrochloric acid was less than that of sulfuric acid because sulfuric acid is stronger than hydrochloric acid (Degirmenci, 2017). This situation can be explained in more detail. Both sulfuric acid and hydrochloric acid are strong acids. Acids decompose into ions due to their dissolution in water. During decomposition, hydrochloric acid dissociates into $\mathrm{H}^{+}$and $\mathrm{Cl}^{-}$, while sulfuric acid dissociates into $\mathrm{H}^{+}$and $\mathrm{HSO}_{4}^{-}$. ${\mathrm{But} \mathrm{HSO}_{4}^{-}}^{-}$ can give another proton, unlike $\mathrm{Cl}^{-}$. So while both are strong acids, one mole of sulfuric acid produces twice as much $\mathrm{H}^{+}$ than one mole of hydrochloric acid. In this sense, even if they are of equal molarity, sulfuric acid becomes more effective by producing more free protons. The fact that $\mathrm{H}_{2} \mathrm{SO}_{4}$ causes faster and greater deterioration than $\mathrm{HCl}$ is due to internal degradation stresses caused by gypsum crystals in the matrix; this triggers cracking, disintegration, and deterioration of the sample. This occurs in addition to the leaching of alkali metals from the matrix and the matrix's dealumination under the influence of $\mathrm{HCl}$ (Vafaei et al., 2018). Under the effect of the hydrochloric acid, 44.98, 23.70, and 18.63 MPa of residual compressive strengths were obtained for sample 20SF after 3, 6, and 12 months, respectively. For sample 10C, the compressive strengths were 40.82, 21.47, and $16.77 \mathrm{MPa}$ after 3, 6, and 12 months, respectively.

The flexural strength results obtained after treatment with acid solutions were checked with the 28-day results (Figs. 7-8). Maximum deterioration was seen in all the samples after 365 days of exposure. The decrease in flexural strength due to the acid effect is attributed to reasons similar to the compressive strength (Mehta \& Siddique, 2017). The flexural strength decrease caused by sulfuric acid was greater than the loss in hydrochloric acid because sulfuric acid is stronger than hydrochloric acid (Degirmenci, 2017). Samples treated with sulfuric acid showed 6.72, 3.73, and 2.07 MPa of residual flexural strength in sample 20SF after 3,6, and 12 months, respectively. In sample 10C, the results were 5.29, 3.22, and 1.64 MPa after 3, 6, and 12 months, respectively. For samples treated with hydrochloric acid, 6.81, 4.70, and 3.43 MPa of residual flexural strength were obtained for sample 20SF after 3, 6, and 12 months, respectively. In sample $10 \mathrm{C}$, the results were 5.74, 4.08, and 3.03 MPa after 3, 6, and 12 months, respectively. The difference in compressive and flexural strength results is due to the silica fume effect. The mixture with $10 \%$ silica fume exhibited a variable performance, while the mixture with $20 \%$ silica fume produced more stable results in terms of compressive and flexural strengths. In this case, the fact that the addition of $20 \%$ silica fume significantly increased the Si/Al ratio effective in geopolymerization plays a role. Thus, significant increases were seen in flexural and compressive strength, rather than variable performance (Uysal et al., 2018). 


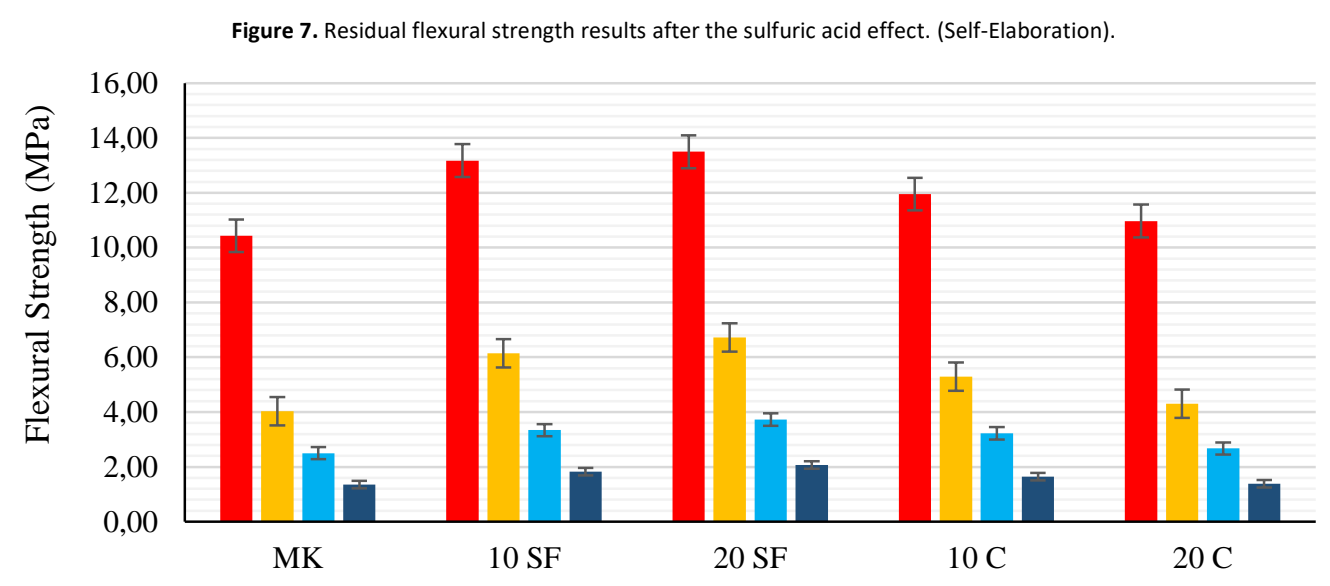

๑ 28 days $\square 3$ months $\square 6$ months $\square 12$ months

Figure 8. Residual flexural strength results after the hydrochloric acid effect. (Self-Elaboration).

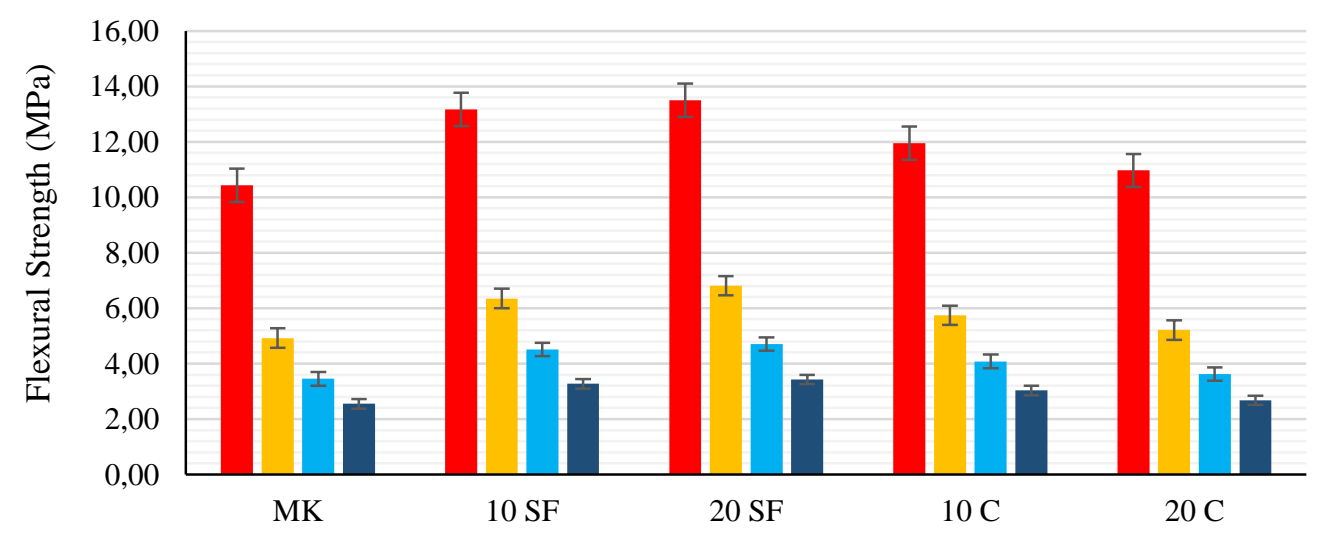

$\square 28$ days $\square 3$ months $\square 6$ months $\square 12$ months

\section{Loss in weight}

A weight-loss increase was observed with an increase in exposure time. When the samples are exposed to sulfuric acid, the calcium hydrated products tend to react with acids to form calcium sulpho-aluminates and calcium sulfates. Calcium sulfate forms gypsum which precipitates on the surface of the specimen forming a weak layer. So the weak layer can dissolve in acid solution and cause weight loss (Rajamane et al., 2012). The acid effect of sulfuric acid and hydrochloric acid resulted in little weight loss in geopolymer samples. This low weight loss is based on the stability of the geopolymer aluminosilicate structure. In his study, Davidovits (2020) reported a weight loss of geopolymer cement between 5 and $8 \%$ and a weight loss between 30 and $60 \%$ in Portland cement samples in acidic media and reported higher stability of geopolymer samples. Song et al. (2005) produced fly ash-based geopolymer samples and only $3 \%$ weight loss was observed after 56 days in $10 \%$ sulfuric acid solution, while $41 \%$ weight loss occurred in traditional concrete samples in only 28 days. Thus, geopolymer mortars appear to be stable and resistant to the effects of sulfuric and hydrochloric acid.

It is also known that geopolymer performance under the influence of acid depends on the average pore diameter (Mehta \& Siddique, 2017). A Na-rich gel can neutralize the acid effect through an acid-base reaction and thus reduce the devastating influences in gel structure. Therefore, Na-rich gel can be counted as another factor that demonstrates the resistance of geopolymers to acid.

The substitution of silica fume reduces weight loss by creating a more compact structure, which prevents acid from entering the mortar. Because sulfuric acid is stronger than hydrochloric acid (Degirmenci, 2017), the weight loss in the $\mathrm{H}_{2} \mathrm{SO}_{4}$ solution was higher than the samples kept in the $\mathrm{HCl}$ solution because the chemical reaction between sulfates 
and calcium compounds forms gypsum crystals and leads to the formation of spalling on surface layers and internal disintegration due to stress (Sata et al., 2012). This indicates that, in addition to acidic salt types, the acid resistance in mortars depends on the type of oxide composition $\left(\mathrm{SiO}_{2}, \mathrm{CaO}\right.$, and $\left.\mathrm{Al}_{2} \mathrm{O}_{3}\right)$ and the chemical stability of the materials used.

Under the effect of sulfuric acid, weight-loss rates were between 0.96 and $1.46 \%$ after 3 months, weight-loss rates after 6 months were between 1.04 and 1.85\%, and weight-loss rates after 12 months were between 2.36 and $3.02 \%$ (Fig. 9). Under the effect of hydrochloric acid, the weight-loss rates of geopolymer mortars after 3 months were between 0.63 and $0.93 \%$, weight-loss rates after 6 months were between 0.94 and $1.39 \%$, and weight-loss rates after 12 months were between 1.88 and $2.43 \%$ (Fig. 10).

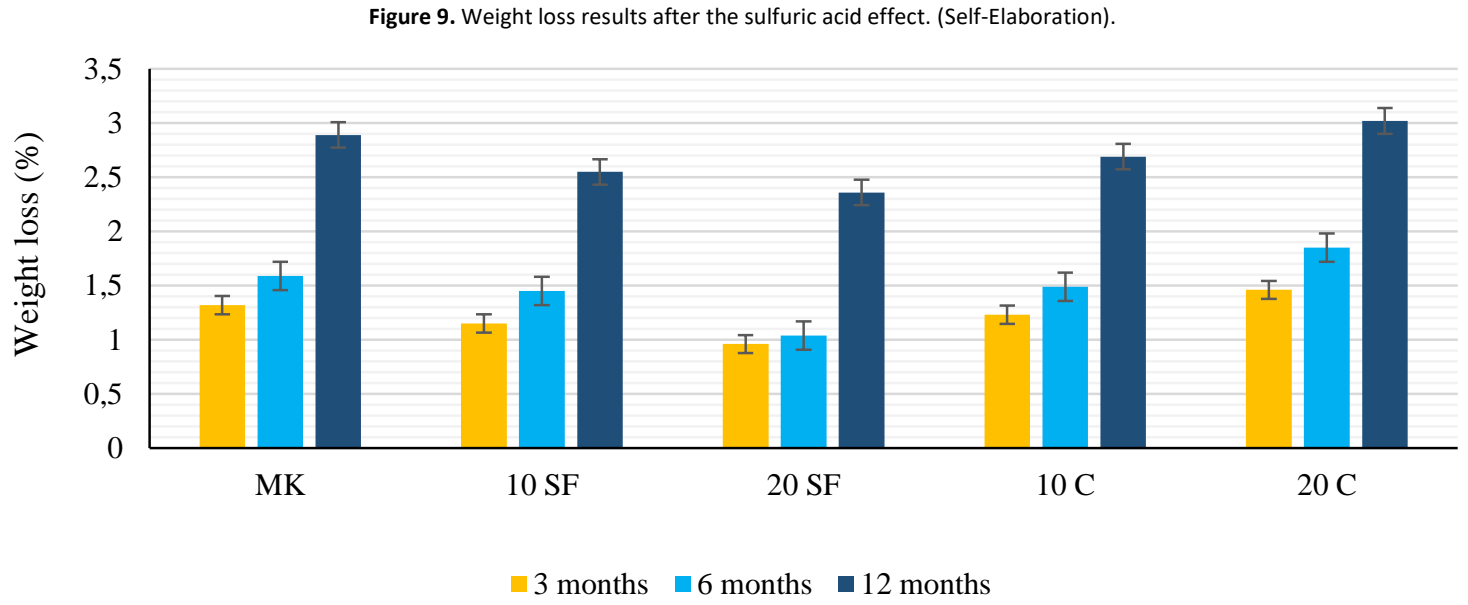

Figure 10. Weight loss results after the hydrochloric acid effect. (Self-Elaboration).

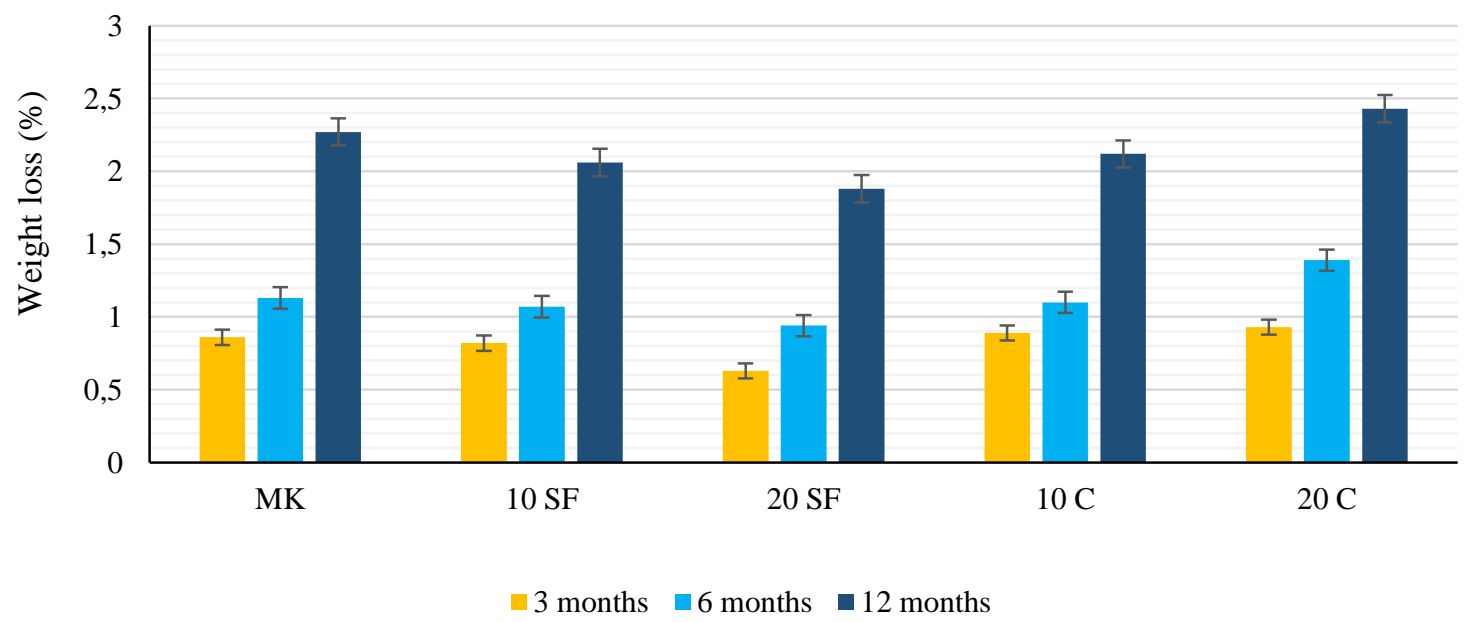

\section{Microstructural analysis}

In this study, SEM analyzes of samples MK, 10C, and 20SF before and after the sulfuric acid effect were performed to examine the condition of the geopolymer composites after the acid effect and compare with the pre-test situation. When the SEM analyzes of the samples before the test are examined, it can be seen that the geopolymeric gel has a good degree of homogeneity. When the samples 10C and 20SF are examined, the continuity of the matrix can be seen. In this case, it can be seen that a good bond is obtained in the geopolymeric system with colemanite and silica fume (Uysal et al., 2018). At the same time, a consistent and compact structure can be seen. SEM analyzes before and after the tests are shown in Figs. 11-12.

The dense microstructure becomes porous caused by acid-induced fragmentation of the Si-O-Al bonds in the geopolymer network after exposure for the samples MK, 10C, and 20SF (Mehta \& Siddique, 2017). Micrographs reveal bubbles and cracks along with needle or larger particles that are occurred in the pores or on broken surfaces. The microcracks are due to the shrinkage of the gel layer, making it easier for sulfuric acid to pass into the interior microstructural areas of the mortar. The disappearance of the observed needle-shaped particles can be explained by the dissolution of 
these species in the acid solution. The presence of sulfur is caused by the reaction between the geopolymer gel and sulfuric acid. When the microstructure of the samples is examined, it can be observed that new crystals have formed resembling the gypsum's crystal structure $\left(\mathrm{CaSO}_{4} .2 \mathrm{H}_{2} \mathrm{O}\right.$ ) (Sata et al., 2012; Song et al., 2005). The gypsum produces a whitish layer with sulfuric acid. The degradation degree in the geopolymer framework of the sample can be shown by the creation of a distinct gypsum phase. This indicates that the acid leaches a significant amount of calcium from the geopolymer gel which reacts with the sulfate ions in the pore solution to create the gypsum precipitate. Thus, the presence of a certain calcium amount in the geopolymer framework accelerates gypsum development. Cracks form together with gypsum crystals to cause compressive and flexural strength loss. The attitude of the geopolymer sample caused by sulfuric acid is linked to its connectivity and pore structure. This conclusion demonstrates that permeability is one of the factors that determine the geopolymer mortar's durability properties, in addition to the fact that Na-rich gel in the sample improves acid resistance (Yankwa Djobo et al., 2016). However, after the acid attack, the samples still maintain the classical metakaolin-based structure of the geopolymer mortar (Criado et al., 2008). Pimraksa et al. (2011) showed that the Si:Al ratio affected the degree of polymerization. In this study, an insignificant decrease in Si:Al ratio was seen in all samples after exposure to sulfuric acid.
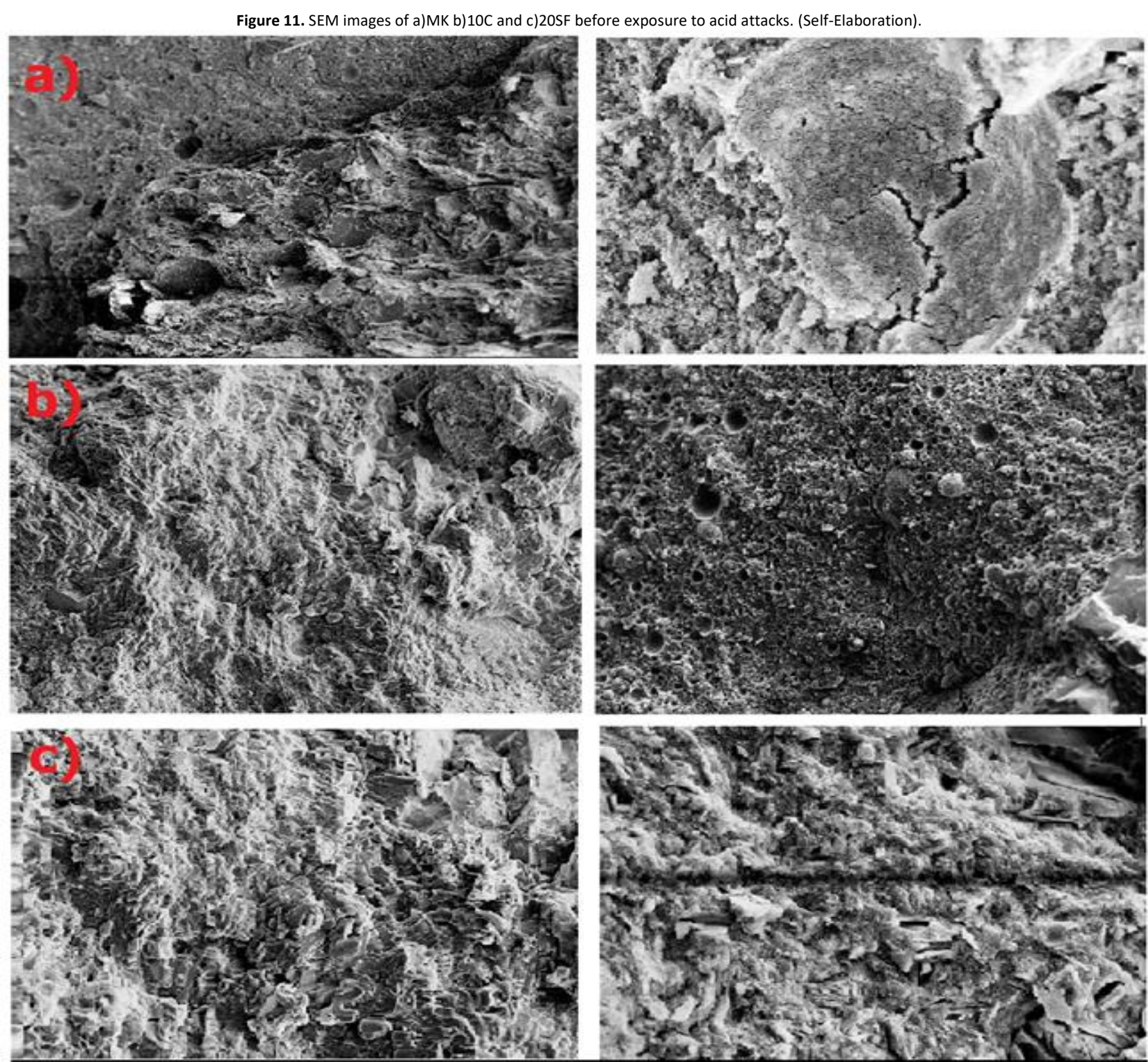

\section{$20 \mu \mathrm{m}$}

$\mathrm{EHT}=10.00 \mathrm{kV}$ WD $=5.5 \mathrm{~mm}$ Signal $\mathrm{A}=\mathrm{SE} 2 \mathrm{Mag}=500 \mathrm{X}$ 
Figure 12. SEM images of a)MK b) $10 \mathrm{C}$ and c)20SF after exposure to sulfuric acid attacks. (Self-Elaboration).
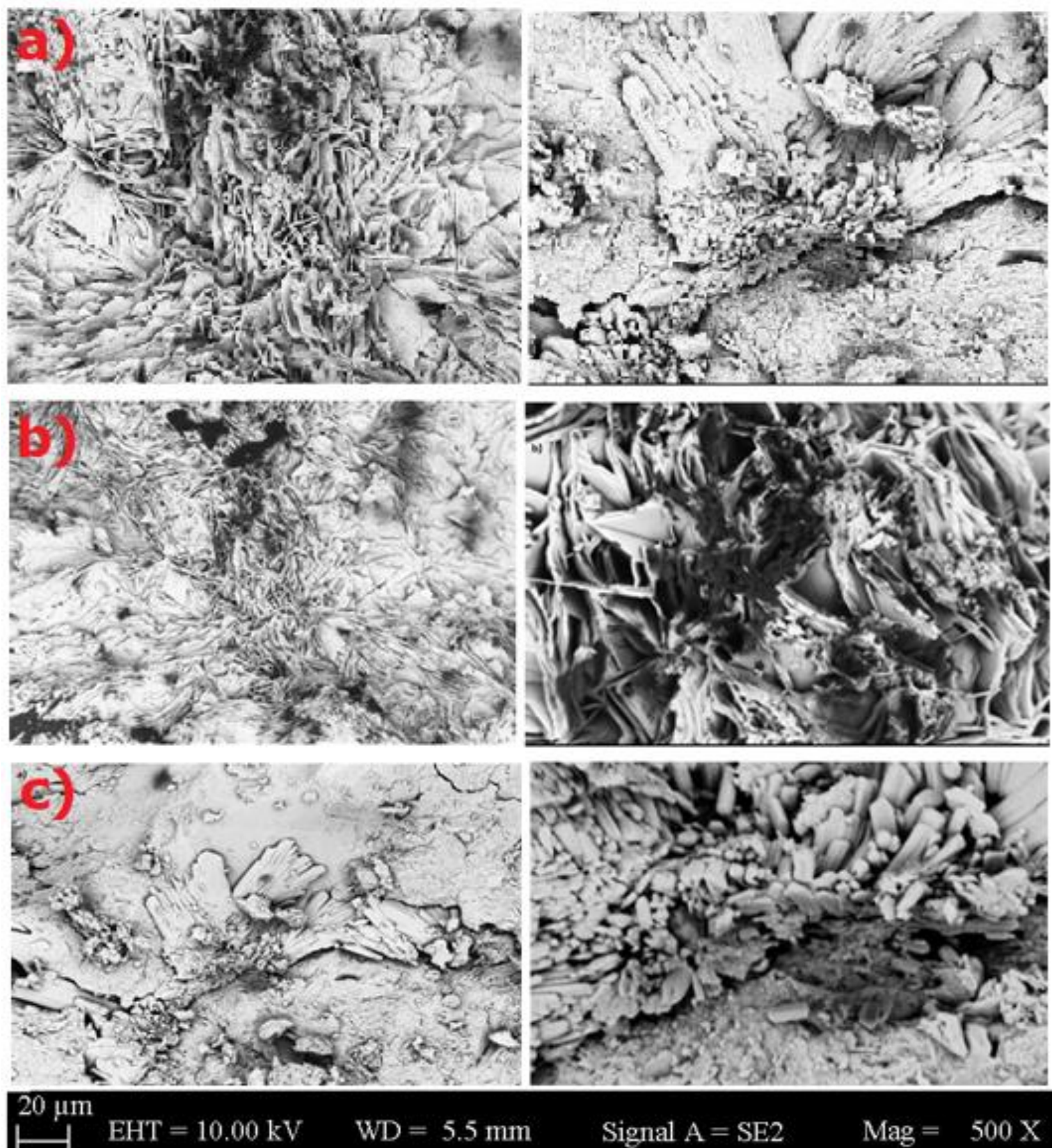

$\mathrm{WD}=5.5 \mathrm{~mm}$

Signal A $=$ SE2

$\mathrm{Mag}=$

$500 \mathrm{x}$

XRD analyzes of the samples MK, 10C, and 20SF were performed before and after the sulfuric acid effect. When XRD analyzes are examined before the acid effect, quartz crystal peaks are seen. Along with quartz, mullite is also obtained in diffraction. The broadband seen at $2 \theta$ between $25^{\circ}$ and $30^{\circ}$ shows satisfactory geopolymer characteristics. In sample $10 \mathrm{C}$, there are no significant differences in the location of the peaks except for slight shifts. In the sample 20SF, since the silicon oxide content increases significantly, quartz peaks are predominantly (Uysal et al., 2018).

Figures 13-14 show the XRD spectrums of MK, 10C, and 20SF before and after the sulfuric acid effect. Samples MK, 20SF, and $10 \mathrm{C}$ are significantly changed by exposure to the sulfuric acid solution. Metakaolin consists mainly of kaolinite followed by quartz and mullite. According to the figures, the XRD analysis of metakaolin-based geopolymers shows a semi-crystalline structure, and some peaks from raw materials are preserved in the patterns. The quartz peaks are preserved at $2 \theta$ between $25^{\circ}$ and $30^{\circ}$ which corresponds to the typical amorphous gel phase after the acid effect (Bouguermouh et al., 2017). After the acid effect, the crystalline components (mullite and quartz) and amorphous phases were examined, and it can be observed that although the peaks decrease, they retain their general structure. These results show that the basic geopolymer matrix is resistant to attack by the acid medium in which it is placed. The 
mechanism for forming geopolymers involves polymerization reactions involving strong aluminosilicate bonds, but with prolonged exposure to sulfuric acid, depolymerization occurs in the aluminosilicate polymers due to degradation. When the previous studies were observed, it was seen that geopolymer concrete had better acid resistance than conventional concrete (Çevik et al., 2018).

Figure 13. X-ray diffraction pattern of a) MK b) $10 \mathrm{C}$ and c) 20SF before sulfuric acid attacks. (Self-Elaboration).
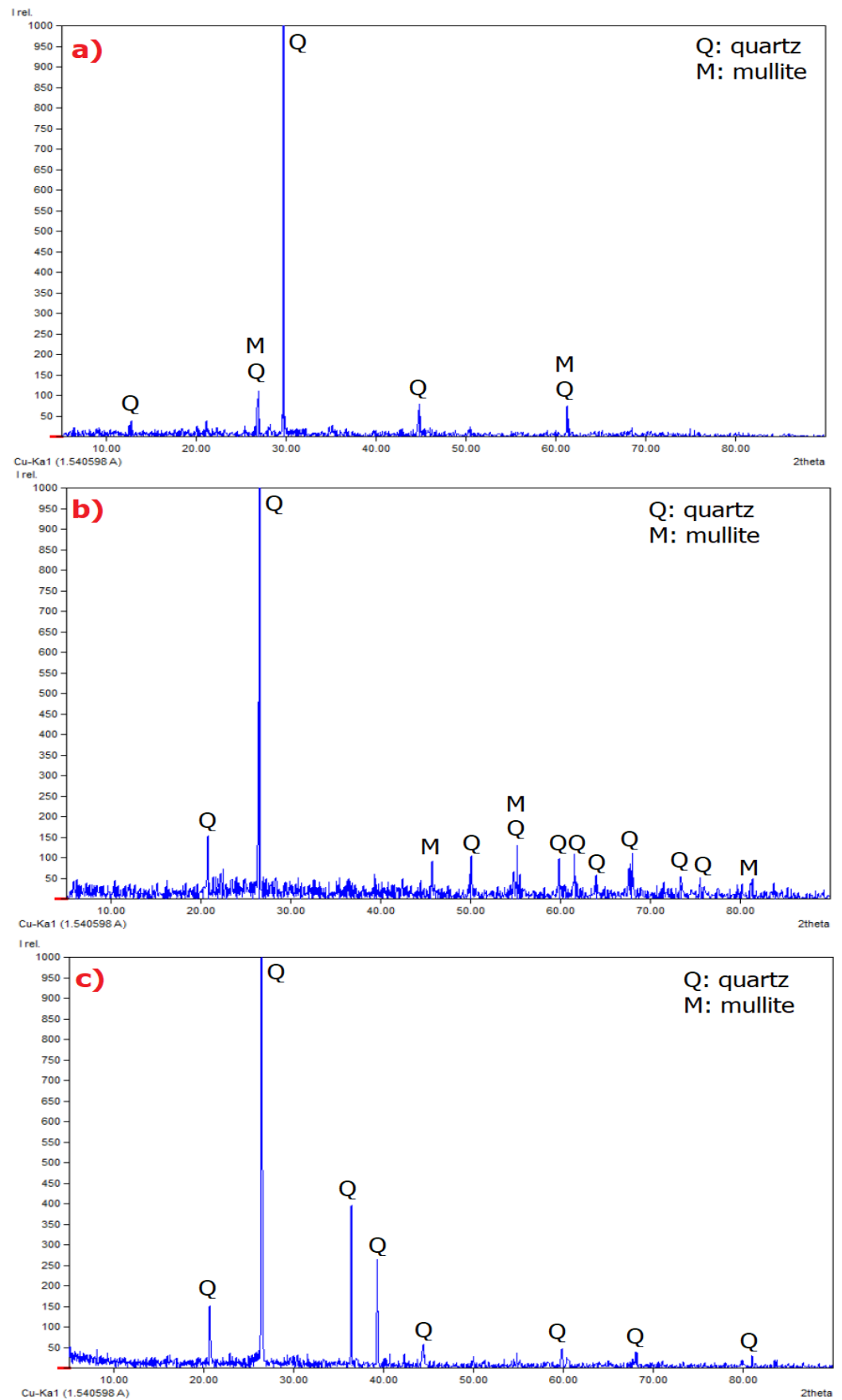
Figure 14. X-ray diffraction pattern of a) MK b) $10 \mathrm{C}$ and c) 20SF after sulfuric acid attacks. (Self-Elaboration).
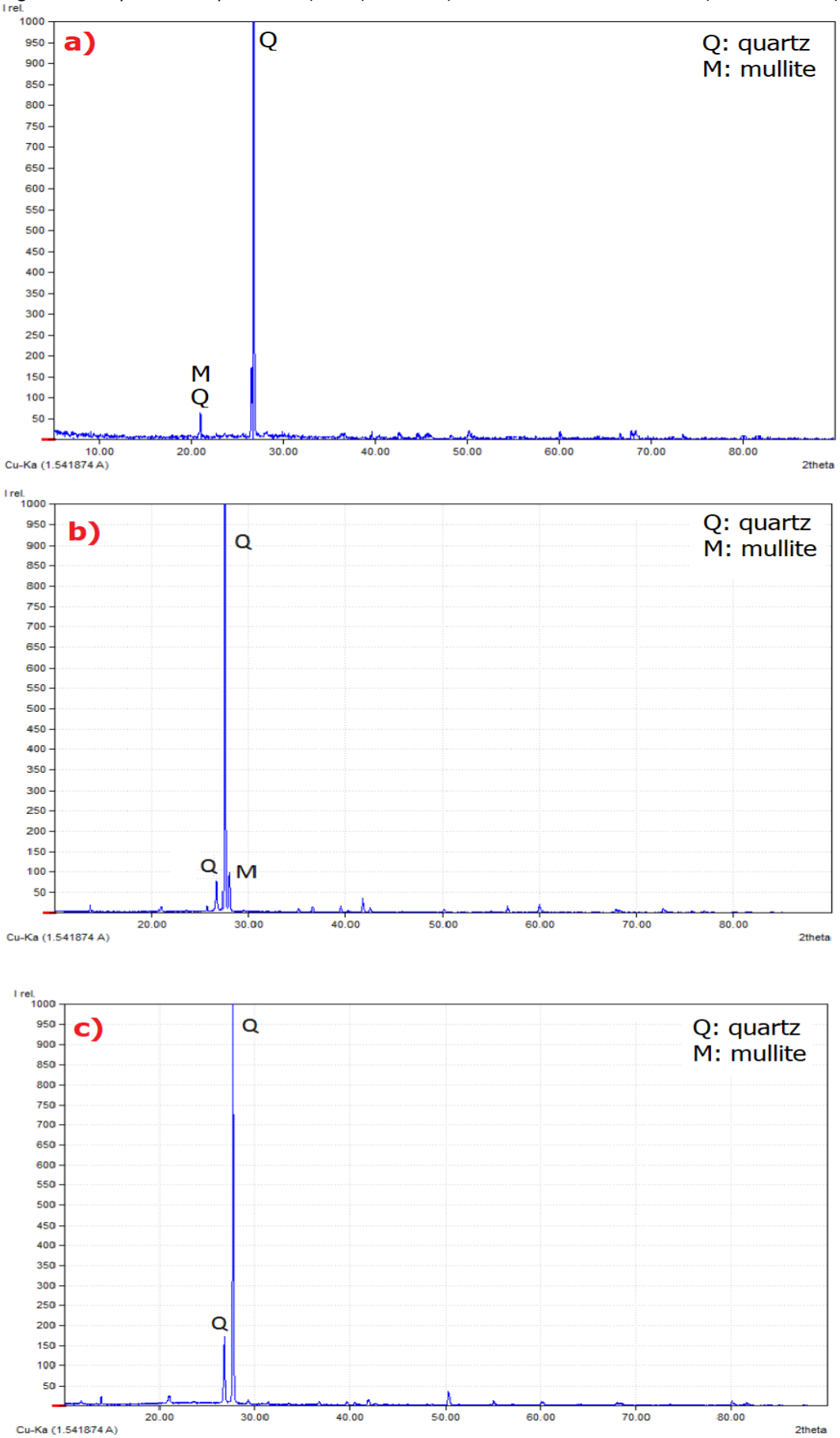

FTIR analyzes of samples MK, 10C, and 20SF before and after sulfuric acid effect are shown in Figures 15-16. The absorbance at $3465.03 \mathrm{~cm}^{-1}$ and $2346.15 \mathrm{~cm}^{-1}$ before the acid effect is due to the asymmetric stretching $(-\mathrm{O}-\mathrm{H})$, which depends on the water and silanol groups. The broad peak centered around $1000 \mathrm{~cm}^{-1}$ provides important information about the formed geopolymerization. This corresponds to Si-O-T ( $\mathrm{T}=\mathrm{Si}$ or Al) vibrations in the geopolymer. While the value of the broad peak in the sample MK is $991.07 \mathrm{~cm}^{-1}$, this value increases to $996.22 \mathrm{~cm}^{-1}$ in sample $10 \mathrm{C}$. In the sample $20 \mathrm{SF}$, this value increases due to the presence of quartz and becomes $1001.03 \mathrm{~cm}^{-1}$. As a result, all series show similar spectra with a small variation. This situation decreases slightly after the sulfuric acid effect. The values of broad peaks after the sulfuric acid effect in samples MK, 10C, and 20SF are $968.32 \mathrm{~cm}^{-1}, 973.72 \mathrm{~cm}^{-1}$, and $977.54 \mathrm{~cm}^{-1}$, respectively. This shows that geopolymer samples are resistant to the sulfuric acid effect (Arslan et al., 2019; Perná et al., 2019; Preethi \& Venkatarama Reddy, 2020). 
Figure 15. FTIR results of samples of a)MK b) $10 \mathrm{C}$ and c)20SF before sulfuric acid attacks. (Self-Elaboration).
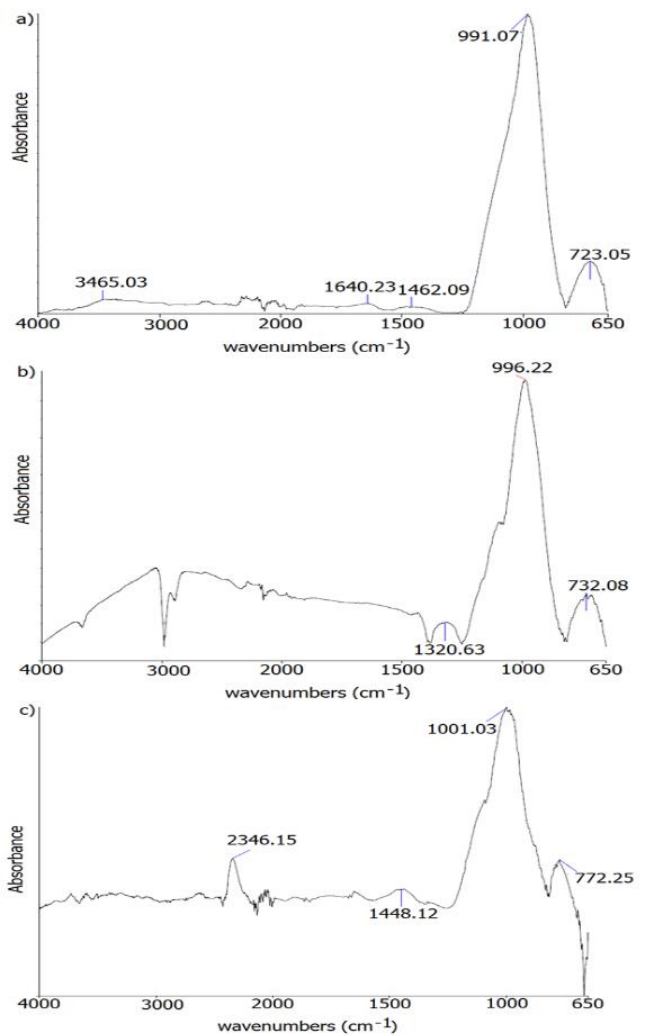

Figure 16. FTIR results of samples of a)MK b)10C and c)20SF after sulfuric acid attacks. (Self-Elaboration).

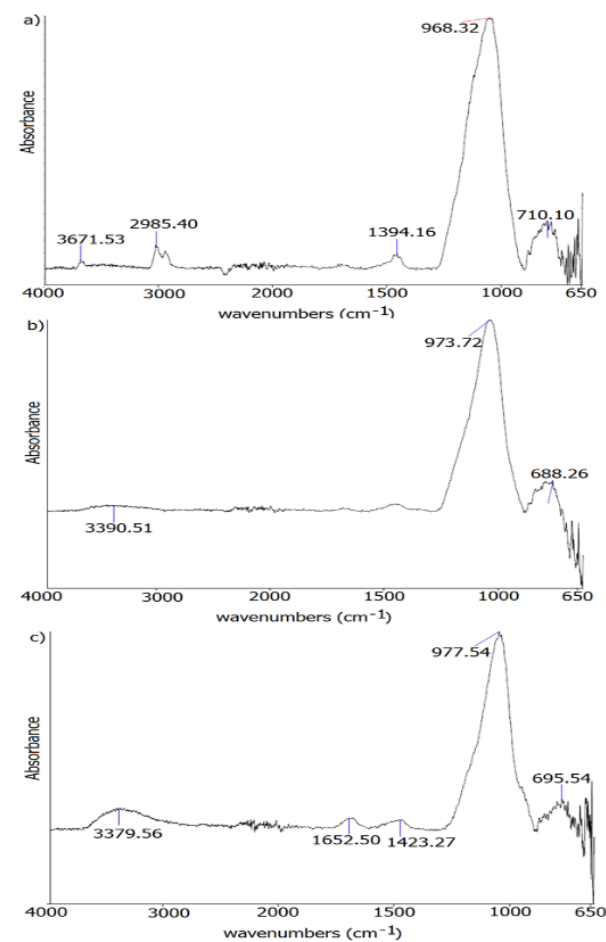

Figure 17 shows the micro-CT analyzes before and after the sulfuric acid effect of samples MK, 10C, and 20SF. The analysis shows a representative cross-sectional view. Significant cracks are not seen before the sulfuric acid effect. The cracks formed are of small size. Shrinkage occurs after the sulfuric acid effect. Incompatibilities between shrinkage trigger crack formation. Similar to loss of compressive and flexural strengths, the crack formation has increased. Components are shown in bold colors due to low or non-X-ray attenuation. This dark color corresponds to air voids. These air voids are formed under the effect of sulfuric acid. It can be also observed that these air voids are lower in 
sample 20SF with the effect of silica fume. As a result, it was determined that the acid effect is limited in geopolymer samples (Aygörmez, Canpolat, Al-mashhadani, et al., 2020d).

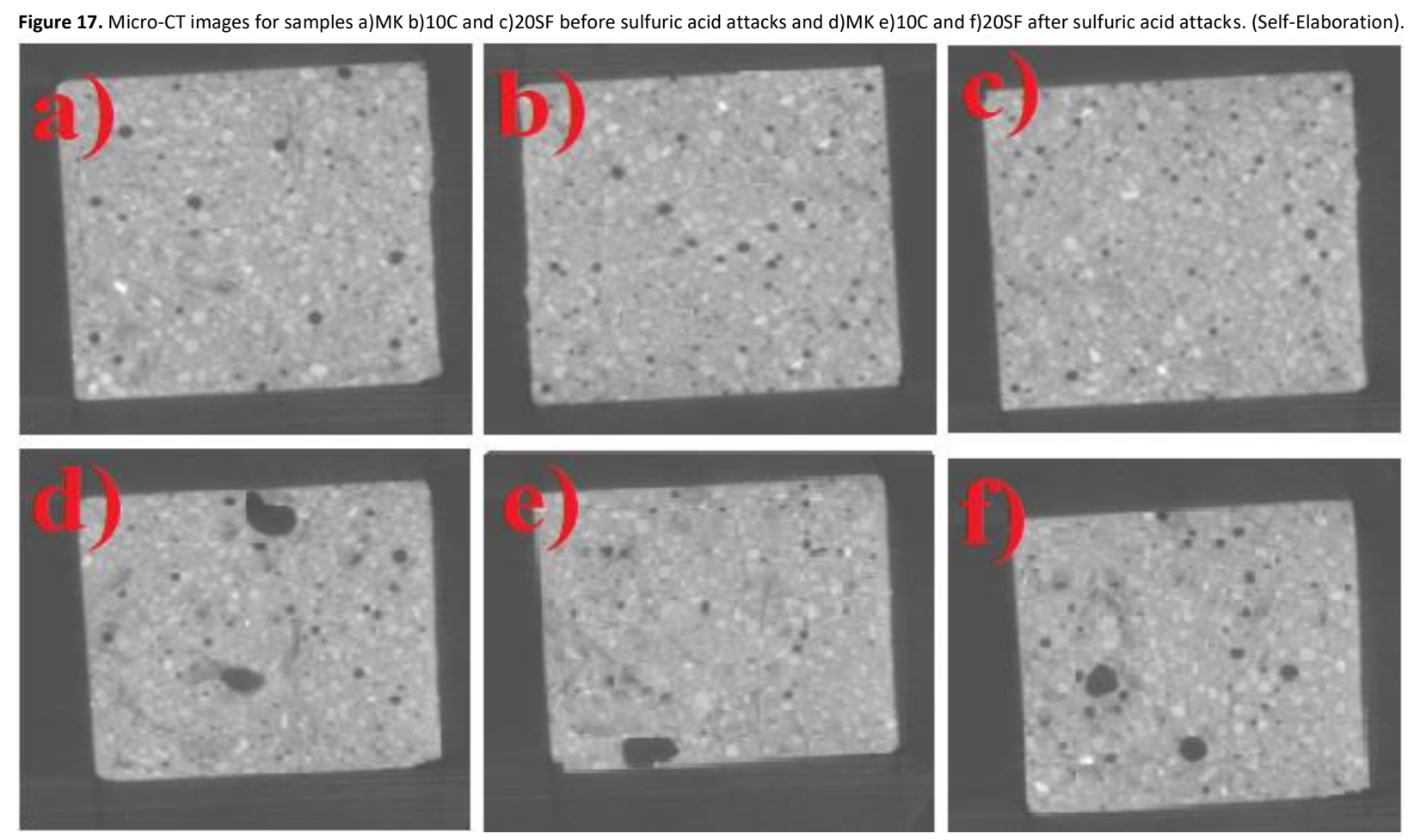

Conclusions

This study investigated the feasibility of adding various materials to a geopolymer matrix to increase the mechanical and durability properties of the samples produced:

- When the results of the tests were examined, it was found that a substitution of $20 \%$ silica fume and $10 \%$ boron waste colemanite was critical according to mechanical properties. Higher utilization of silica fume reduces workability, while higher utilization of colemanite results in poor performance.

- The geopolymer samples suffered a loss of compressive and flexural strengths at the end of one year but were shown to maintain their stability. Samples $10 \mathrm{C}$ and 20SF, which had higher initial compressive and flexural strengths before exposure to the acid solution, were found to have high residual compressive and flexural strengths at the end of the test. The fact that sulfuric acid is stronger than hydrochloric acid made it more effective.

- When the results were examined, sample 20SF has achieved an increase of $15 \%-40 \%$ in compressive strength and $30 \%-60 \%$ in flexural strength compared to the control sample against the acid effect. Sample 10C, on the other hand, increased the compressive strength between $5 \%-20 \%$ and the flexural strength by $15 \%-30 \%$ compared to the control sample against the acid effect.

- The main reason for higher stability in geopolymer samples is the existence of the oxy-aluminum bridge (-Al-Si-O) which is resistant to the acid effect, and the calcium oxide ratio is lower thus the formation of gypsum and ettringite is less. This prevents acid-induced expansion, cracking, and spreading of geopolymer samples as compared to Portland cement.

- An increase in weight loss was observed with prolonged exposure. The microstructures of the samples after exposure to sulfuric acid were highly porous with the presence of microcracks due to the Si-O-Al bonds degradation as confirmed by SEM analysis; however, the samples still maintained the basic structure of classic geopolymers as evidenced by XRD, FTIR and micro-CT analyzes.

\section{Acknowledgments}

This work was supported by the research fund of the Yildiz Technical University - Turkey, the authors would like to express their sincere gratitude to the scientific research coordination unit for their financial support to the project (Project number: 2016-05-01-DOP04). 
Afridi, S., Sikandar, M. A., Waseem, M., Nasir, H., \& Naseer, A. (2019). Chemical durability of superabsorbent polymer (SAP) based geopolymer mortars (GPMs). Construction and Building Materials, 217, 530-542. https://doi.org/10.1016/j.conbuildmat.2019.05.101

Aguiar, J. B., Camões, A., \& Moreira, P. M. (2008). Coatings for concrete protection against aggressive environments. Journal of Advanced Concrete Technology, 6(1), 243-250. https://doi.org/10.3151/jact.6.243

Aiken, T. A., Kwasny, J., Sha, W., \& Soutsos, M. N. (2018). Effect of slag content and activator dosage on the resistance of fly ash geopolymer binders to sulfuric acid attack. Cement and Concrete Research, 111(May), 23-40. https://doi.org/10.1016/j.cemconres.2018.06.011

Ali, N., Canpolat, O., Aygörmez, Y., \& Al-Mashhadani, M. M. (2020). Evaluation of the 12-24 mm basalt fibers and boron waste on reinforced metakaolin-based geopolymer. Construction and Building Materials, 251, 118976. https://doi.org/10.1016/j.conbuildmat.2020.118976

Almusallam, A. A., Khan, F. M., Dulaijan, S. U., \& Al-Amoudi, O. S. B. (2003). Effectiveness of surface coatings in improving concrete durability. Cement and Concrete Composites, 25(4-5 SPEC), 473-481. https://doi.org/10.1016/S0958-9465(02)00087-2

Arslan, A. A., Uysal, M., Yılmaz, A., Al-mashhadani, M. M., Canpolat, O., Şahin, F., \& Aygörmez, Y. (2019). Influence of wetting-drying curing system on the performance of fiber reinforced metakaolin-based geopolymer composites. Construction and Building Materials, 225, 909-926. https://doi.org/10.1016/j.conbuildmat.2019.07.235

Aygörmez, Y., Canpolat, O., \& Al-mashhadani, M. M. (2020a). A survey on one-year strength performance of reinforced geopolymer composites. Construction and Building Materials, 264. https://doi.org/10.1016/j.conbuildmat.2020.120267

Aygörmez, Y., Canpolat, O., \& Al-mashhadani, M. M. (2020b). Assessment of geopolymer composites durability at one-year age. Journal of Building Engineering, 32(April). https://doi.org/10.1016/j.jobe.2020.101453

Aygörmez, Y., Al-mashhadani, M. M., \& Canpolat, O. (2020c). High-temperature effects on white cement-based slurry infiltrated fiber concrete with metakaolin and fly ash additive. Revista de La Construccion, 19(2), 324-333. https://doi.org/10.7764/RDLC.19.2.324

Aygörmez, Y., Canpolat, O., Al-mashhadani, M. M., \& Uysal, M. (2020d). Elevated temperature, freezing-thawing and wetting-drying effects on polypropylene fiber reinforced metakaolin based geopolymer composites. Construction and Building Materials, 235. https://doi.org/10.1016/j.conbuildmat.2019.117502

Bani Ardalan, R., Joshaghani, A., \& Hooton, R. D. (2017). Workability retention and compressive strength of self-compacting concrete incorporating pumice powder and silica fume. Construction and Building Materials, 134, 116-122. https://doi.org/10.1016/j.conbuildmat.2016.12.090

Belmokhtar, N., Ammari, M., Brigui, J., \& Ben allal, L. (2017). Comparison of the microstructure and the compressive strength of two geopolymers derived from Metakaolin and an industrial sludge. Construction and Building Materials, 146, 621-629. https://doi.org/10.1016/j.conbuildmat.2017.04.127

Bouguermouh, K., Bouzidi, N., Mahtout, L., Pérez-Villarejo, L., \& Martínez-Cartas, M. L. (2017). Effect of acid attack on microstructure and composition of metakaolin-based geopolymers: The role of alkaline activator. Journal of Non-Crystalline Solids, 463, $128-137$. https://doi.org/10.1016/j.jnoncrysol.2017.03.011

Celik, A., Yilmaz, K., Canpolat, O., Al-mashhadani, M. M., Aygörmez, Y., \& Uysal, M. (2018). High-temperature behavior and mechanical characteristics of boron waste additive metakaolin based geopolymer composites reinforced with synthetic fibers. Construction and Building Materials, 187, 1190-1203. https://doi.org/10.1016/j.conbuildmat.2018.08.062

Chang, J. J., Yeih, W., \& Hung, C. C. (2005). Effects of gypsum and phosphoric acid on the properties of sodium silicate-based alkali-activated slag pastes. Cement and Concrete Composites, 27(1), 85-91. https://doi.org/10.1016/j.cemconcomp.2003.12.001

Chen, L., Wang, Z., Wang, Y., \& Feng, J. (2016). Preparation and properties of alkali activated metakaolin-based geopolymer. Materials, 9(9), 1-12. https://doi.org/10.3390/ma9090767

Chindaprasirt, P., Rattanasak, U., \& Taebuanhuad, S. (2013). Resistance to acid and sulfate solutions of microwave-assisted high calcium fly ash geopolymer. Materials and Structures/Materiaux et Constructions, 46(3), 375-381. https://doi.org/10.1617/s11527-012-9907-1

Criado, M., Fernández-Jiménez, A., Palomo, A., Sobrados, I., \& Sanz, J. (2008). Effect of the SiO2/Na2O ratio on the alkali activation of fly ash. Part II: 29Si MAS-NMR Survey. Microporous and Mesoporous Materials, 109(1-3), 525-534. https://doi.org/10.1016/j.micromeso.2007.05.062

Çevik, A., Alzeebaree, R., Humur, G., Niş, A., \& Gülşan, M. E. (2018). Effect of nano-silica on the chemical durability and mechanical performance of fly ash based geopolymer concrete. Ceramics International, 44(11), 12253-12264. https://doi.org/10.1016/j.ceramint.2018.04.009

Davidovits, J. (2020). Geopolymer Chemistry and Applications. 5-th edition. In J. Davidovits.-Saint-Quentin, France (Issue January 2008).

Degirmenci, F. N. (2017). Effect of sodium silicate to sodium hydroxide ratios on durability of geopolymer mortars containing natural and artificial pozzolans. Ceramics - Silikaty, 61(4), 340-350. https://doi.org/10.13168/cs.2017.0033

Elyamany, H. E., Abd Elmoaty, A. E. M., \& Elshaboury, A. M. (2018). Magnesium sulfate resistance of geopolymer mortar. Construction and Building Materials, 184, 111-127. https://doi.org/10.1016/j.conbuildmat.2018.06.212

Khan, H. A., Castel, A., Khan, M. S. H., \& Mahmood, A. H. (2019). Durability of calcium aluminate and sulphate resistant Portland cement based mortars in aggressive sewer environment and sulphuric acid. Cement and Concrete Research, 124, 105852. https://doi.org/10.1016/j.cemconres.2019.105852

Kula, I., Olgun, A., Erdogan, Y., \& Sevinc, V. (2001). Effects of colemanite waste, cool bottom ash, and fly ash on the properties of cement. Cement and Concrete Research, 31(3), 491-494. https://doi.org/10.1016/S0008-8846(00)00486-5 
Kwasny, J., Aiken, T. A., Soutsos, M. N., McIntosh, J. A., \& Cleland, D. J. (2018). Sulfate and acid resistance of lithomarge-based geopolymer mortars. Construction and Building Materials, 166, 537-553. https://doi.org/10.1016/j.conbuildmat.2018.01.129

Mehta, A., \& Siddique, R. (2017). Sulfuric acid resistance of fly ash based geopolymer concrete. Construction and Building Materials, 146, $136-143$. https://doi.org/10.1016/j.conbuildmat.2017.04.077

Mobili, A., Belli, A., Giosuè, C., Bellezze, T., \& Tittarelli, F. (2016). Metakaolin and fly ash alkali-activated mortars compared with cementitious mortars at the same strength class. Cement and Concrete Research, 88, 198-210. https://doi.org/10.1016/j.cemconres.2016.07.004

Nematollahi, B., Qiu, J., Yang, E. H., \& Sanjayan, J. (2017). Microscale investigation of fiber-matrix interface properties of strain-hardening geopolymer composite. Ceramics International, 43(17), 15616-15625. https://doi.org/10.1016/j.ceramint.2017.08.118

Omrane, M., Kenai, S., Kadri, E. H., \& Aït-Mokhtar, A. (2017). Performance and durability of self compacting concrete using recycled concrete aggregates and natural pozzolan. Journal of Cleaner Production, 165, 415-430. https://doi.org/10.1016/j.jclepro.2017.07.139

Perná, I., Šupová, M., Hanzlíček, T., \& Špaldoňová, A. (2019). The synthesis and characterization of geopolymers based on metakaolin and high LOI straw ash. Construction and Building Materials, 228. https://doi.org/10.1016/j.conbuildmat.2019.116765

Pimraksa, K., Chindaprasirt, P., Rungchet, A., Sagoe-Crentsil, K., \& Sato, T. (2011). Lightweight geopolymer made of highly porous siliceous materials with various $\mathrm{Na2O} / \mathrm{Al} 2 \mathrm{O} 3$ and $\mathrm{SiO} 2 / \mathrm{Al} 2 \mathrm{O} 3$ ratios. Materials Science and Engineering A, 528(21), 6616-6623. https://doi.org/10.1016/j.msea.2011.04.044

Preethi, R. K., \& Venkatarama Reddy, B. V. (2020). Experimental investigations on geopolymer stabilised compressed earth products. Construction and Building Materials, 257, 119563. https://doi.org/10.1016/j.conbuildmat.2020.119563

Rajamane, N. P., Nataraja, M. C., Lakshmanan, N., Dattatreya, J. K., \& Sabitha, D. (2012). Sulphuric acid resistant ecofriendly concrete from geopolymerisation of blast furnace slag. Indian Journal of Engineering and Materials Sciences, 19(5), 357-367.

Rivera, J. F., De Gutierrez, R. M., Mejia, J. M., \& Gordillo, M. (2014). Hybrid cement based on the alkali activation of by-products of coal. Revista de La Construccion, 13(2), 31-39. https://doi.org/10.4067/s0718-915×2014000200004

Sata, V., Sathonsaowaphak, A., \& Chindaprasirt, P. (2012). Resistance of lignite bottom ash geopolymer mortar to sulfate and sulfuric acid attack. Cement and Concrete Composites, 34(5), 700-708. https://doi.org/10.1016/j.cemconcomp.2012.01.010

Sevim, U. K. (2011). Colemanite ore waste concrete with low shrinkage and high split tensile strength. Materials and Structures/Materiaux et Constructions, 44(1), 187-193. https://doi.org/10.1617/s11527-010-9618-4

Singh, B., Ishwarya, G., Gupta, M., \& Bhattacharyya, S. K. (2015). Geopolymer concrete: A review of some recent developments. Construction and Building Materials, 85, 78-90. https://doi.org/10.1016/j.conbuildmat.2015.03.036

Song, X. J., Marosszeky, M., Brungs, M., \& Munn, R. (2005, April). Durability of fly ash based geopolymer concrete against sulphuric acid attack. In International Conference on Durability of Building Materials and Components (Vol. 10).

Tahri, W., Abdollahnejad, Z., Mendes, J., Pacheco-Torgal, F., \& de Aguiar, J. B. (2017). Cost efficiency and resistance to chemical attack of a fly ash geopolymeric mortar versus epoxy resin and acrylic paint coatings. European Journal of Environmental and Civil Engineering, 21(5), 555-571. https://doi.org/10.1080/19648189.2015.1134674

Uysal, M., Al-mashhadani, M. M., Aygörmez, Y., \& Canpolat, O. (2018). Effect of using colemanite waste and silica fume as partial replacement on the performance of metakaolin-based geopolymer mortars. Construction and Building Materials, 176 . https://doi.org/10.1016/j.conbuildmat.2018.05.034

Vafaei, M., Allahverdi, A., Dong, P., \& Bassim, N. (2018). Acid attack on geopolymer cement mortar based on waste-glass powder and calcium aluminate cement at mild concentration. Construction and Building Materials, 193, 363-372. https://doi.org/10.1016/j.conbuildmat.2018.10.203

Wu, Z., Khayat, K. H., \& Shi, C. (2019). Changes in rheology and mechanical properties of ultra-high performance concrete with silica fume content. Cement and Concrete Research, 123(October 2018), 105786. https://doi.org/10.1016/j.cemconres.2019.105786

Yang, T., Zhu, H., \& Zhang, Z. (2017). Influence of fly ash on the pore structure and shrinkage characteristics of metakaolin-based geopolymer pastes and mortars. Construction and Building Materials, 153, 284-293. https://doi.org/10.1016/j.conbuildmat.2017.05.067

Yankwa Djobo, J. N., Elimbi, A., Kouamo Tchakouté, H., \& Kumar, S. (2016). Mechanical properties and durability of volcanic ash based geopolymer mortars. Construction and Building Materials, 124, 606-614. https://doi.org/10.1016/j.conbuildmat.2016.07.141

Zhang, Z., Wang, H., Zhu, Y., Reid, A., Provis, J. L., \& Bullen, F. (2014). Using fly ash to partially substitute metakaolin in geopolymer synthesis. Applied Clay Science, 88-89, 194-201. https://doi.org/10.1016/j.clay.2013.12.025 